\title{
Composition of Human Atheroma Collected from Coronary Arteries during Coronary Artery Bypass Surgery*
}

\author{
Mayank Acharya1, Pranab Karmaker², Md. Moniruzzaman², Abu Hasan², Sumiya Aktar2, \\ Asit Baran Adhikary3, Mala Khan"\# \\ ${ }^{1}$ CTVS, National Trauma Center, Kathmandu, Nepal \\ ${ }^{2}$ Bangladesh Reference Institute for Chemical Measurements, Dhaka, Bangladesh \\ ${ }^{3}$ Bangabandhu Sheikh Mujib Medical University, Dhaka, Bangladesh \\ Email: mayankacharya@gmail.com,pranab@bricm.gov.bd,mzamancep@yahoo.com, hasan.bricm@gmail.com, \\ sumiyaacct@gmail.com,drasit2005@yahoo.com, \#bricmdg@yahoo.com
}

How to cite this paper: Acharya, M., Karmaker, P., Moniruzzaman, M., Hasan, A., Aktar, S., Adhikary, A.B. and Khan, M. (2021) Composition of Human Atheroma Collected from Coronary Arteries during Coronary Artery Bypass Surgery. Advances in Bioscience and Biotechnology, 12, 323-336. https://doi.org/10.4236/abb.2021.1210021

Received: August 29, 2021

Accepted: October 25, 2021

Published: October 28, 2021

Copyright $\odot 2021$ by author(s) and Scientific Research Publishing Inc. This work is licensed under the Creative Commons Attribution International License (CC BY 4.0).

http://creativecommons.org/licenses/by/4.0/

\begin{abstract}
Coronary arteries supply blood and nutrients to the heart. Coronary Artery Disease (CAD) develops by narrowing of the arteries. Once the inner walls of the arteries are damaged, fatty deposits made of cells, connective tissue elements, lipids and debris decrease their lumens which block blood flow to distal tissues. This process is called arteriosclerosis. This study intends to detect the composition of human coronary atheroma collected from the arteries during bypass surgeries in Bangladesh. It shows that all lesions are present in the advanced types, namely, type 4, 5 and 6 . Infrequently thrombotic materials and necrotic debris were found in type 6 plaque. The mean length of plaque was $3.36 \pm 1.71 \mathrm{~cm}$ and mean weight was $0.13 \pm 0.12 \mathrm{gm}$. Insufficient lipid was obtained from each atheroma. Few raised areas were lipid laden whereas most of the strands were fibrous. Biochemical assessment was formidable. The cholesterol composition of coronary plaque ranged between $0.20 \%-9.83 \%$ with mean $3.06 \% \pm 2.09 \%$ and total fatty acids ranged between $0.47 \%-3.04 \%$ with mean $1.31 \% \pm 0.63 \%$. The most abundant fatty acid was oleic acid (unsaturated) closely followed by palmitic acid (saturated). The mean calcium content was 41,180.20 $\pm 34,918.59 \mathrm{ppm}$ and ranged from $1148.00-140,311.00$ ppm or, $0.115 \%-14.031 \%$. This study was undertaken to detect the composition of human coronary atheroma in Bangladesh which revealed that it depended upon the type of lesion.
\end{abstract}

*These authors contributed equally to this work.

\#Corresponding author. 
Keywords

Atheroma, Coronary Artery Disease, Arteriosclerosis

\section{Introduction}

Coronary arteries are vessels that supply blood and nutrients to the heart. Arterial supply of the heart is provided by the right and the left coronary arteries, which arise from the ascending aorta immediately above the aortic valve. The coronary arteries, lying within the sub epicardium, distribute over the surface of the heart. There are two major branches, right and the left coronary arteries which supply the heart distinctly and behave as either anatomic or functional end arteries. Coronary Artery Disease (CAD) is narrowing of the coronary arteries caused by thickening and loss of elasticity of their walls (arteriosclerosis) that, when sufficiently severe, limits blood flow to the myocardium. Initially, the disease limits only coronary flow reserve (increase in flow that normally accompanies increased myocardial oxygen demands), but when sufficiently advanced, CAD reduces blood flow through the affected artery and even at the rest. In its most severe form, atherosclerotic CAD occludes the coronary artery [1].

Atherosclerosis is defined as a disease of the arteries characterized by their deposition of fatty material on their inner walls, which consists of cells, connective-tissue elements, lipids, and debris which decreases their lumen to cause impairment of blood flow to distal tissues [2]. The plaques may also cause coronary syndromes by becoming unstable and triggering coronary thrombosis. The term atherosclerosis is derived from Latin language which means gruel ("athero") and hardening ("sclerosis") of the arteries. The atherogenic process is characterized by dysfunction of endothelial lining of the vessel, followed by, inflammation of the vascular wall, followed by, buildup of lipids and their aggregation, cholester$\mathrm{ol}$, and inflammatory cells in the vessel wall and accumulation of cellular debris within the intimal and sub intimal layers of the vessel. These processes result in plaque formation, and remodeling of the arterial wall. The underlying mechanisms are uncertain, and amongst many, the most widely accepted theory is the "response-to-injury" hypothesis [3]. According to WHO data published in 2012, Coronary Heart Disease death in Bangladesh reached 507,000 or 5.7\% of total deaths. In Bangladesh, it is the fourth leading cause of death after tuberculosis, lower respiratory infections and, chronic obstructive pulmonary disease [4].

The disease prevalence is rising even in the rural areas [5]. Coronary artery disease (CAD) in south Asian population which also includes Bangladesh is increasing, affecting the people at a relatively younger age with severe and diffuse form of lesions [6]. Compared to other people, South Asians have higher rates of CAD more than two folds at any given level of conventional risk factors like obesity, hypertension, cigarette smoking, and high cholesterol. CAD amongst South Asians can be broadly categorized into 3 distinct forms: Type I or malignant type 
occurs in individuals less than 50 years with marked prematurity and severity. Type II occurs in older individuals more than 65 years with high levels of conventional risk factors and low levels of emerging risk factors. Type III or mixed variety occurs between the ages of 50 years and 65 years and is accompanied by varying combinations of conventional and emerging risk factors [7].

Atheroma contains of mainly macrophages, fibrous tissue, calcium and lipids [8]. Lipids are a group of naturally occurring molecules, and are classified by International Lipid Classification and Nomenclature Committee into eight categories, viz; fatty acyls, glycerolipids, glycerophospholipids, sphingolipids, saccharolipids, polyketides (derived from condensation of ketoacyl subunits), prenol lipids (derived from condensation of isoprene subunits) and, sterol lipids [9]. Fatty acid is a carboxylic acid with a long aliphatic chain, which is either saturated or unsaturated based on carbon double bond and length, and trans fatty acid, type of unsaturated fatty acid, are rarely found naturally and comprise of artificially processed fatty acids. In its free form it is called as fatty acid, and with various moieties it is known as fatty acyls; e.g.: triacylglycerol or triglyceride or TG, which is the most common type of fat in the body, is a glycerol with three fatty acids. Glycerolipids are Glycerol (polyol containing three hydroxyl $(-\mathrm{OH})$ groups) of a single glycerol molecule forming ester bond with carboxyl group $(-\mathrm{COOH})$ of three fatty acids. Denoted as mono-, di-, and tri-substituted glycerols example: monoglycerides, diglycerides and, triglycerides [10].

The case of coronary artery disease is significantly higher in South Asian population as compared to others; 2 folds higher than the Whites and 4 folds higher than the Chinese, and is rising [11]. Atheromatous plaques are responsible as the main etiology of Myocardial Infarction (MI) and a detailed understanding of the composition would yield us a better targeted strategy to combat the problem, both clinically and possibly pharmacologically. To the best of my knowledge, no single study has been done in Bangladesh to quantify the composition of lipid of atheroma taken from human coronary arteries during operation.

So, the purpose of the cross sectional observational study is to assess and quantify, by whatever means possible through fractionation of lipids at Bangladesh Council of Scientific and Industrial Research and Bangabandhu Sheikh Mujib Medical University, the qualitative and quantitative aspects of lipids and calcium in human atheroma, as well as it may help future researchers to be able to know what components can be modified by drugs. Also the purpose of this study is to perform histopathological examination of the atheroma to reveal its constituents at Department of Pathology, Bangabandhu Sheikh Mujib Medical University.

\section{Materials and Methods}

It was a cross sectional observational type of study. Purposive sampling method was applied for this study. The study community was the patients who were diagnosed with coronary artery disease who underwent atherectomy during CABG 
in the department of Cardiac Surgery, D-Block, Bangabandhu Sheikh Mujib Medical University, Shahbag, Dhaka and Al Helal Specialized Hospital (AHSH), Mirpur-10, Dhaka. The study was conducted within the period of 24 months commencing from March 2016 to February 2018. Total number of cases $=80$ (Eighty).

\subsection{Laboratory Diagnosis and Analysis}

1) Department of Pathology, B-Block, Shahbag, Banglabandhu Sheikh Mujib Medical University.

2) Designated Reference Institute for Chemical Measurements (DRICM), Bangladesh Council of Scientific and Industrial Research (BCSIR), Kudrat-i-khuda Road, Dhaka.

\subsection{Selection Criteria}

- Inclusion Criteria:

* All patients who underwent coronary endarterectomy were included in my study.

- Exclusion Criteria:

* Patients who did not undergo endarterectomy were not taken in my study.

Patients who did not give consent to participate in the study were excluded.

\subsection{Data Collection Tool}

All relevant data were collected from each patient who fulfilled the inclusion criteria. Data were collected in data collection sheet by Interviewer administered semi structured questionnaire. Informed written consent was obtained.

\subsection{Study Procedure}

\subsubsection{Collection of Atheroma}

The atheromas were collected from the operating theater in the following manner. Standard median sternotomy and pericardiotomy was performed. The plaque was identified which usually revealed itself grossly or as focus of neovascularization. A $1.5-2 \mathrm{~cm}$ nick was made in the coronary vessel and atheroma was removed slowly (atherectomy) and grafting by conduit was done on that site. The length of atheroma was measured and a section of atheroma was cut and kept for histopathological examination and remaining section was vialed up in normal saline and were then taken to Designated Reference Institute for Chemical Measurements at Bangladesh Council of Scientific and Industrial Research where they were first numbered and labeled separately and stored at $-20^{\circ} \mathrm{C}$ using Siemens KA58NA75 freezer, for analysis at a suitable day.

\subsubsection{Laboratory Analysis of Atheromatous Plaque}

Taking one atheroma as example, the analysis is explained. The atheroma was thawed at room temperature then dried using Whatman ashless filter paper (Grade 41, Sigma Aldrich) for 5 mins. After drying the sample was weighed by 
laboratory precision weighing machine (AL 204, Mettler Toledo) and three sections were cut from it for analysis. After this fractionation was performed for each component lipid or mineral from each section using specific solvents and procedures provided by the DRICM laboratory.

\subsection{Statistical Analysis and Result}

Data were analyzed according to the objective. For continuous variables like cholesterol, fatty acids and calcium content, relative area of cholesterol cleft and calcifications, mean and standard deviation, Pearson's correlation, Wilcoxon's signed ranks test and ANOVA were seen and the results were also presented in tables and diagram. For discrete and categorical variables like age, gender and drug history, results were shown by using frequency distribution and chi-squared $\left(\chi^{2}\right)$ test.

\subsection{Ethical Consideration}

Ethical approval was taken from Institutional Review Board (IRB). Informed written consent was collected from each individual before starting the data collection. The collected data were kept completely confidential and only were used for study purpose. Patient had right to agree, disagree or withdraw from the study at any time during the study.

\section{Results and Discussion}

A total of 80 (eighty) patients were selected for this study. The atherosamples obtained from these patients were analyzed by histopathology and biochemical tests. In biochemical tests the percentages of lipids (cholesterol and fatty acids) were seen.

\subsection{Distribution of Patients by Age}

Table 1 shows the mean age for all 80 patients were $53.68 \pm 8.26$ years. The maximum incidence of disease was found in $51-60$ years in total number of patients. The second predominant age group was 41 - 50 years. Among them $85 \%$ were male and $15 \%$ were female. The mean body mass index of total 80 patients was $24.75 \pm 2.34 \mathrm{Kg} / \mathrm{m}^{2}$.

\subsection{Distribution of Patients by Duration of Intake of Statin before Undergoing CABG}

Table 2 shows distribution of 80 patients by duration of statin use before operative procedure. Among 80 patients 5\% took statins for less than one year, 36.2\% took for 6 months to 1 year and $58.8 \%$ patients took for more than 1 year.

\subsection{Distribution of Site of Atherectomy Vessel}

Table 3 shows distribution of 80 patients by site of atherectomy. Right coronary Artery (RCA) atheretomy was performed in $48.8 \%$ patients $(n=39)$. Left Anterior 
Table 1. Demographic characteristics of patients.

\begin{tabular}{|c|c|c|}
\hline \multirow{2}{*}{ Age in Completed (Years) } & \multicolumn{2}{|c|}{ Total } \\
\hline & $\mathbf{N}$ & $\%$ \\
\hline$\leq 40$ & 06 & 7.5 \\
\hline $41-50$ & 25 & 31.2 \\
\hline $51-60$ & 36 & 45.0 \\
\hline$>60$ & 13 & 16.2 \\
\hline Total & 80 & 100.0 \\
\hline Mean \pm SD & $53.68 \pm 8.26$ & \\
\hline Min - Max & $32-71$ & \\
\hline \multirow{2}{*}{ Sex } & \multicolumn{2}{|c|}{ Total } \\
\hline & $\mathbf{N}$ & $\%$ \\
\hline Male & 68 & 85.0 \\
\hline Female & 12 & 15.0 \\
\hline Total & 80 & 100.0 \\
\hline \multirow{2}{*}{ BMI $\left(\mathrm{kg} / \mathrm{m}^{2}\right)$} & \multicolumn{2}{|c|}{ Total } \\
\hline & $\mathbf{N}$ & $\%$ \\
\hline Normal & 34 & 42.5 \\
\hline Over weight & 46 & 57.5 \\
\hline Total & 80 & 100.0 \\
\hline Mean \pm SD & $24.75 \pm 2.34$ & \\
\hline
\end{tabular}

Data were expressed as number, percentage and Mean \pm SD. $\mathrm{N}=$ Total number of patients; $\mathrm{SD}=$ Standard Deviation.

Table 2. Distribution of patients by duration of intake of statin before undergoing CABG.

\begin{tabular}{ccc}
\hline Duration of Statin & \multicolumn{2}{c}{ Total } \\
\cline { 2 - 3 } & $\mathrm{N}$ & $\%$ \\
\hline$<6$ months & 04 & 5.0 \\
6 months - 1 year & 29 & 36.2 \\
$>1$ year & 47 & 58.8 \\
Total & $\mathbf{8 0}$ & 100.0
\end{tabular}

Data were presented as number and percentage. $\mathrm{N}=$ Total number of patients; CABG = Coronary artery bypass grafting.

Table 3. Distribution of site of atherectomy vessel.

\begin{tabular}{ccc}
\hline Name of atherectomy Vessel & \multicolumn{2}{c}{ Total } \\
\cline { 2 - 3 } Right coronary artery & $\mathbf{N}$ & 48.8 \\
Left anterior descending artery & 39 & 35.0 \\
Posterior decending artery & 28 & 18.8 \\
Obtuse marginal artery & 15 & 8.8 \\
Diagonal artery & 07 & 6.3 \\
Ramus intermedius artery & 05 & 1.3
\end{tabular}

Data were presented as number and percentage. $\mathrm{N}=$ Total number of patients. 
Descending (LAD) artery atherectomy was performed in 35\% patients $(\mathrm{n}=28)$. Posterior descending artery atherectomy was done in $18.8 \%$ patients $(n=15)$. Obtuse Marginal artery atherectomy was done $8.8 \%$ patients $(n=7)$ and Diagonal artery atherectomy was done $6.3 \%$ patients $(n=5)$. There was also one case of Ramus intermedius atheretomy (1.3\%).

\subsection{Distribution of Length and Dry Weight of Atheroma}

Table 4 shows Distribution of Atheroma Length in centimeters and Atheroma Weight (after drying) in grams of 80 patients. Among 80 patients the mean length was $3.36 \pm 1.71$ centimeters and the mean weight was $0.13 \pm 0.12$ grams.

\subsection{Mean \pm SD of Atheroma Variables Analyzed Biochemically $(\mathrm{N}=80)$}

Table 5 shows distribution of lipid variables and total calcium in an atheroma of eighty patients. The total lipids were expressed as a percentage of its weight in grams. Calcium expressed as ppm of the total weight. The mean total cholesterol was found to be $3.06 \% \pm 2.09 \%$ and range between $0.20 \%-9.83 \%$. Total Fatty acid mean was $1.31 \% \pm 0.36 \%$ and range was $0.47 \%-3.04 \%$. The saturated fatty acid mean was $0.64 \% \pm 0.32 \%$ and range was $0.20 \%-1.54 \%$. Mean of total unsaturated fatty acid was found to be $0.66 \% \pm 0.33 \%$ and range $0.00 \%-1.50 \%$.

Table 4. Distribution of length and dry weight of atheroma $(\mathrm{N}=80)$.

\begin{tabular}{ccc}
\hline Variables & Mean \pm SD & Range \\
\hline Length (centimeters) & $3.36 \pm 1.71$ & $0.4-9.7$ \\
Weight (grams) & $0.13 \pm 0.12$ & $0.01-0.58$ \\
\hline
\end{tabular}

Data were presented as mean $\pm \mathrm{SD} . \mathrm{SD}=$ Standard Deviation; $\mathrm{N}=$ Total number of patients.

Table 5. Mean \pm SD of atheroma variables analyzed biochemically $(\mathrm{N}=80)$.

\begin{tabular}{ccc}
\hline Variables & Mean \pm SD & Range \\
\hline Total Cholesterol (\%) & $3.06 \pm 2.09$ & $0.20-9.83$ \\
Total Calcium (ppm) & $41,180.20 \pm 34,918.59$ & $1148.00-140,311.00$ \\
Total Fatty Acid (\%) & $1.31 \pm 0.63$ & $0.47-3.04$ \\
Total Saturated Fatty Acid (\%) & $0.64 \pm 0.32$ & $0.20-1.54$ \\
Total Unsaturated Fatty Acid (\%) & $0.66 \pm 0.33$ & $0.00-1.50$ \\
Total Mono Unsaturated Fatty Acid (\%) & $0.43 \pm 0.23$ & $0.00-1.18$ \\
Total Poly Unsaturated Fatty Acid (\%) & $0.24 \pm 0.17$ & $0.00-1.14$ \\
Palmitic Acid (\%) & $0.41 \pm 0.20$ & $0.13-0.98$ \\
Stearic Acid (\%) & $0.23 \pm 0.16$ & $0.00-0.99$ \\
Oleic Acid (\%) & $0.42 \pm 0.23$ & $0.00-1.18$ \\
Erucic Acid (\%) & $0.02 \pm 0.03$ & $0.00-0.25$ \\
Linoleic Acid (\%) & $0.24 \pm 0.17$ & $0.00-1.14$
\end{tabular}

Data were presented as number and mean \pm SD. $\mathrm{N}=$ Total number of patients. $\mathrm{ppm}=$ parts per million. 
Total mono unsaturated fatty acid mean was $0.43 \% \pm 0.23 \%$ and range $0.00 \%$ $1.18 \%$. Total poly unsaturated fatty acid mean was found to be $0.24 \% \pm 0.17 \%$ and in the range between $0.00 \%-1.14 \%$. The mean of palmitic acid was $0.41 \% \pm$ $0.20 \%$ and range $0.13 \%-0.98 \%$. Stearic acid mean was $0.23 \% \pm 0.16 \%$ and range $0.00 \%-0.99 \%$. Oleic Acid mean was $0.42 \% \pm 0.23 \%$ and range $0.00 \%-1.18 \%$. Erucic Acid mean was $0.02 \% \pm 0.03 \%$ and range was $0.00 \%-0.23 \%$ and mean of linoleic Acid was $0.24 \% \pm 0.17 \%$ and range was $0.00 \%-1.14 \%$.

The mean of total calcium was $41,180.20 \pm 34,918.59 \mathrm{ppm}$ and range was within 1148.00 - 140,311.00 ppm.

\subsection{Comparison of Mean \pm SD of Total Saturated Fatty Acid and Total Unsaturated Fatty Acid}

The total saturated fatty acid and total unsaturated fatty acid was compared (Table 6).

The mean total saturated fatty acid was $0.64 \% \pm 0.32 \%$ with mean rank 37.77 and mean total unsaturated fatty acid was $0.66 \% \pm 0.33 \%$ with mean rank 40.47 and the difference was statistically significant (p-value 0.016). The median was 0.53 for total saturated fatty acids, and 0.57 for total unsaturated fatty acids.

\subsection{Comparison of Mean \pm SD of Total Mono Unsaturated Fatty Acid and Total Poly Unsaturated Fatty Acid}

The total monounsaturated fatty acid and total polyunsaturated fatty acid was compared (Table 7). The mean total monounsaturated fatty acid was $0.42 \% \pm$ $0.23 \%$ with mean rank 41.42 and mean total polyunsaturated fatty acid was $0.24 \% \pm 0.17 \%$ with mean rank 11.42 and the difference was highly statistically significant $(\mathrm{p}<0.001)$. The median of total monounsaturated fatty acids was 0.39 and median of total polyunsaturated fatty acids was 0.20 .

\subsection{The Frequency Distribution of Stages of Atheroma $(\mathrm{N}=\mathbf{8 0})$}

The frequency distribution of Type of Plaque is shown (Table 8).

Predominantly plaque was found in Type V in 43 (53.8\%) patients. It was followed by Type IV in 26 (32.5\%) patients and 11 (13.8\%) in Type VI. None were found in other types.

Table 6. Comparison of Mean \pm SD of total saturated fatty acid and total unsaturated fatty acid.

\begin{tabular}{cccc}
\hline & \multicolumn{2}{c}{ Total Fatty Acid (N = 80) } & \\
\cline { 2 - 3 } & $\begin{array}{c}\text { Total Saturated Fatty } \\
\text { Acid (\%) }\end{array}$ & $\begin{array}{c}\text { Total Unsaturated } \\
\text { Fatty Acid (\%) }\end{array}$ & \\
\hline Mean \pm SD & $0.64 \pm 0.32$ & $0.66 \pm 0.33$ & \\
Mean Rank & 37.77 & 40.47 & $0.016^{\mathrm{s}}$ \\
Median & 0.53 & 0.57 & \\
\hline
\end{tabular}

Data were presented as number and mean $\pm \mathrm{SD}$. ${ }^{*} \mathrm{p}$ value reached from Wilcoxon signed ranks test and $\mathrm{p}$ values $<0.05$ accepted as significant. $\mathrm{SD}=$ Standard Deviation; $\mathrm{N}=$ Total number of patients; $\mathrm{S}=$ Significant. 
Table 7. Comparison of Mean \pm SD of total mono unsaturated fatty acid and total poly unsaturated fatty acid.

\begin{tabular}{cccc}
\hline & \multicolumn{2}{c}{ Total Unsaturated Fatty Acid (N = 80) } & \\
\cline { 2 - 3 } & $\begin{array}{c}\text { Total Mono Unsaturated } \\
\text { Fatty Acid (\%) }\end{array}$ & $\begin{array}{c}\text { Total Poly Unsaturated } \\
\text { Fatty Acid (\%) }\end{array}$ & \\
\hline Mean \pm SD & $0.42 \pm 0.23$ & $0.24 \pm 0.17$ & \\
Mean Rank & 41.42 & 11.42 & $<0.001^{\mathrm{S}}$ \\
Median & 0.39 & 0.20 & \\
\hline
\end{tabular}

Data were presented as number and mean $\pm \mathrm{SD}$. ${ }^{*} \mathrm{P}$ value reached from Wilcoxon signed ranks test and $\mathrm{p}$ values $<0.05$ accepted as significant. $\mathrm{SD}=$ Standard Deviation; $\mathrm{N}=$ Total number of patients; $\mathrm{S}=$ Significant.

Table 8. Distribution of type of plaque $(\mathrm{N}=80)$.

\begin{tabular}{ccc}
\hline Type of plaque & Frequency & Percent (\%) \\
\hline I & 00 & 0.0 \\
II & 00 & 0.0 \\
III & 00 & 0.0 \\
IV & 26 & 32.5 \\
V & 43 & 53.8 \\
VI & 11 & 13.8 \\
Total & 80 & 100.0 \\
\hline
\end{tabular}

Data were presented in numbers and percentage. $\mathrm{N}=$ Total patients. Note: Type I: initial lesion; Type II: fatty streak; Type III: preatheroma; Type IV: atheroma; Type V: fibroatheroma; Type VI: complicated lesion.

\subsection{Correlation Matrix of Age of Patient, Length of Atheroma, Weight of Atheroma, Total Cholesterol of Atheroma, Total Fatty Acids of Atheroma ( $\mathrm{N}=80)$}

Correlation matrix of variables is shown in Table 9. There is a negative correlation of age of patient with length of atheroma, weight of atheroma, total cholesterol of atheroma, and total fatty acids of atheroma. $(r=-0.049,-0.102,-0.323$, and -0.184 respectively), with correlation of age and total cholesterol in atheroma being statistically significant $(\mathrm{p}=0.004)$. All other correlation is not statistically significant. There is a positive correlation between length of atheroma and weight of atheroma $(r=0.341)$, and is statistically highly significant $(p=0.002)$. Also, there is a weak positive correlation between length and total fatty acid in atheroma $(r=0.053)$ both not statistically significant. However, there is a weak negative correlation between length of atheroma and total cholesterol of atheroma $(r=-0.061)$ which is not statistically significant. There are weak positive correlations between weight of atheroma and total cholesterol $(r=0.18$ respectively), however, they are not statistically significant. There is a weak negative correlation between weight of atheroma and fatty acids in atheroma $(r=-0.031)$, which is not statistically significant. Between total cholesterol of atheroma and total fatty acids there is a weak positive correlation $(r=0.177)$, which is statistically non-significant. 
Table 9. Correlation matrix of age and other quantitative variables $(\mathrm{N}=80)$.

\begin{tabular}{|c|c|c|c|c|c|c|c|}
\hline Variables & Test & $\begin{array}{c}\text { Age } \\
\text { (years) }\end{array}$ & $\begin{array}{c}\text { Length } \\
\text { (cms) }\end{array}$ & $\begin{array}{c}\text { Weight } \\
\text { (gm) }\end{array}$ & $\begin{array}{c}\text { Cholesterol } \\
(\%)\end{array}$ & $\begin{array}{c}\text { Calcium } \\
\text { (ppm) }\end{array}$ & $\begin{array}{c}\text { Fatty Acids } \\
\text { (\%) }\end{array}$ \\
\hline \multirow{2}{*}{ Age } & $\mathrm{r}$ & - & - & & & & \\
\hline & $\mathrm{p}$ value & - & - & & & & \\
\hline \multirow{2}{*}{ Length } & $\mathrm{r}$ & -0.049 & - & & & & \\
\hline & $\mathrm{p}$ value & 0.664 & - & & & & \\
\hline \multirow{2}{*}{ Weight } & $\mathrm{r}$ & -0.102 & $0.341^{*}$ & - & & & \\
\hline & $\mathrm{p}$ value & 0.366 & $0.002^{* *}$ & - & & & \\
\hline \multirow{2}{*}{ Total Cholesterol } & $\mathrm{r}$ & $-0.323^{*}$ & -0.061 & 0.18 & - & & \\
\hline & $\mathrm{p}$ value & $0.004^{* *}$ & 0.590 & 0.876 & - & & \\
\hline \multirow{2}{*}{ Total Fatty Acid } & $\mathrm{r}$ & -0.184 & 0.053 & -0.031 & 0.177 & -0.144 & - \\
\hline & $\mathrm{p}$ value & 0.102 & 0.638 & 0.785 & 0.116 & 0.203 & - \\
\hline
\end{tabular}

${ }^{*}$ Correlation is significant at 0.01 level (2-tailed), p-value attained from Pearson's correlation (" $r$ ") and set at $<0.05$ level of significance. $r=$ Pearson Correlation Co-efficient; Data presented in numbers and percentages; $\mathrm{S}=$ significant.

\subsection{Correlation Scatter Diagram of Total Cholesterol of Atheroma with Length and Weight of Atheroma}

Figure 1 shows weak negative correlation between total cholesterol of atheroma with length of atheroma. $\mathrm{r}=-0.061,(\mathrm{p}$-value $=0.590)$ and weight of atheroma. $\mathrm{r}$ $=0.18,(\mathrm{p}$-value $=0.876)$.

\subsection{Correlation Scatter Diagram of Total Fatty Acids of Atheroma with Length and Weight of Atheroma}

Figure 2 shows weak positive correlation between total fatty acids of atheroma with length of atheroma. $r=0.053,(p$-value $=0.638)$ and weight of atheroma. $r$ $=-0.031$, $(\mathrm{p}$-value $=0.785)$.

\subsection{Comparison between Type of Atheroma, and Mean \pm SD of Total Cholesterol and Total Fatty Acids}

Table 10 shows Analysis of Variance (ANOVA) testing of correlation between Mean \pm SD of total cholesterol, total calcium and total fatty acids and type of atheroma. Mean of total cholesterol, total calcium and total fatty acids of atheroma were significantly different among three type of plaque ( $\mathrm{p} \leq 0.001,0.003$, $<0.001$ respectively).

\subsection{Association of Type of Plaque with Diabetic and Non Diabetic Patients}

Table 11 shows association of Type of Plaque with Diabetic Patients. There were 39 patients with diabetes and 41 without diabetes $(\mathrm{N}=80)$. Among diabetic patients 19 patients (48.7\%) with diabetes had Type IV plaque compared to 14 patients $(35.9 \%)$ had Type V plaque and 6 patients (15.4\%) had Type VI plaque. 

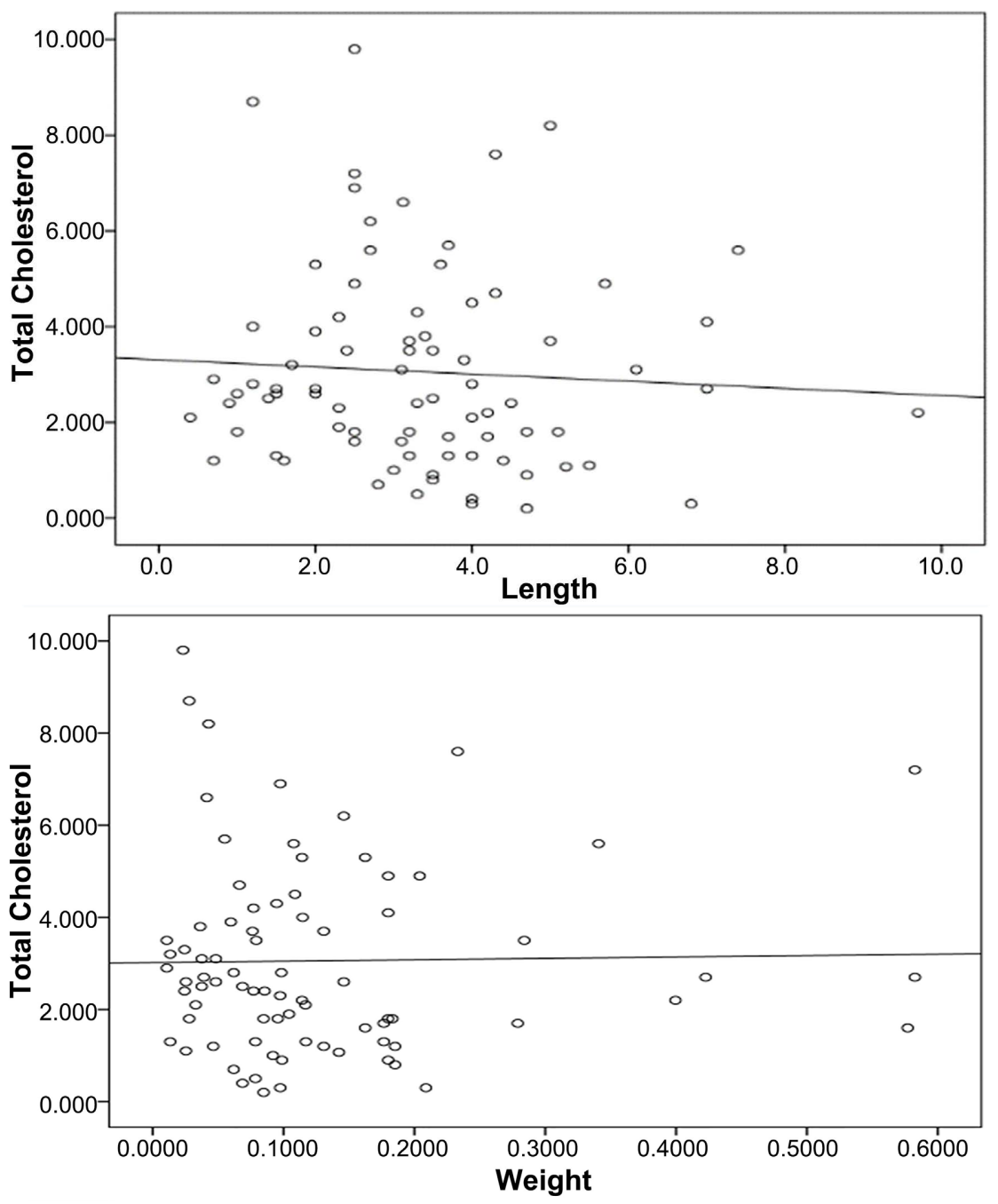

Figure 1. Correlation of total cholesterol of atheroma with length and weight of atheroma.

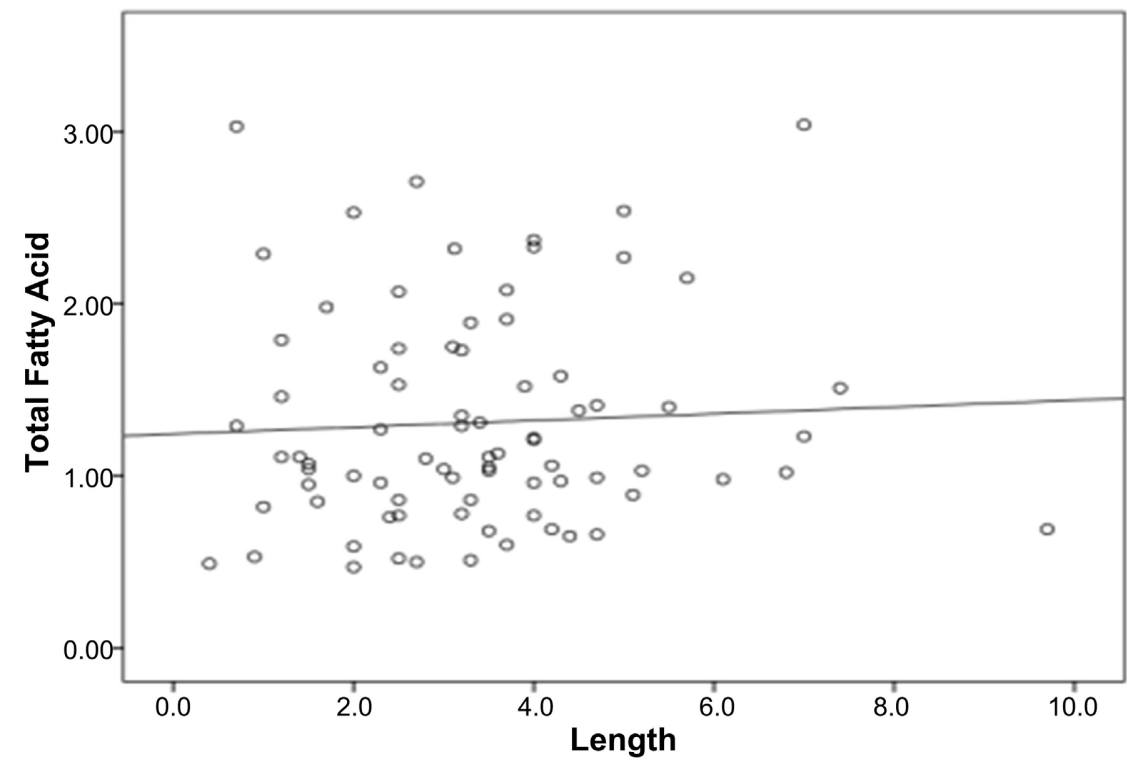




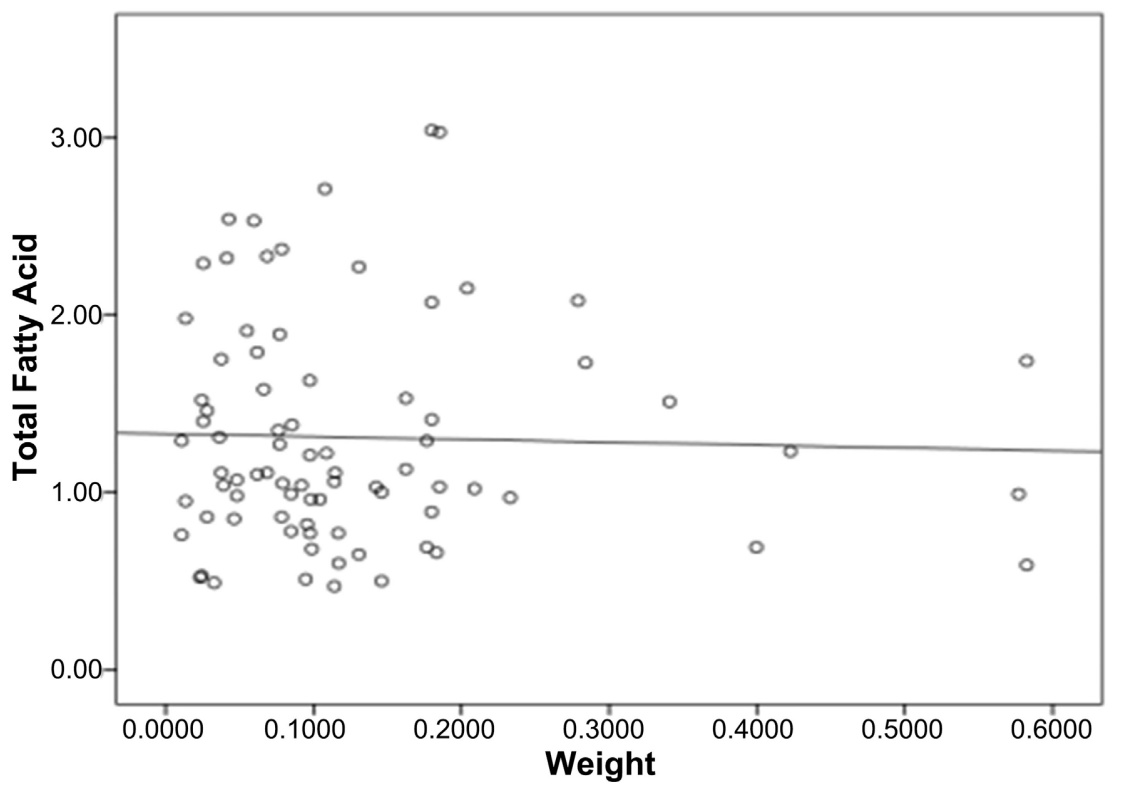

Figure 2. Correlation of length of total fatty acids of atheroma with length and weight of atheroma.

Table 10. Comparison between type of atheroma, and Mean \pm SD of total cholesterol and total fatty acids $(\mathrm{N}=80)$.

\begin{tabular}{ccccc}
\hline Atheroma Variables & $\begin{array}{c}\text { Type IV } \\
\mathbf{n}=\mathbf{2 6}\end{array}$ & $\begin{array}{c}\text { Type V } \\
\mathbf{n}=\mathbf{4 3}\end{array}$ & $\begin{array}{c}\text { Type VI } \\
\mathbf{n}=11\end{array}$ & p-value \\
\hline Total Cholesterol & $4.43 \pm 1.76$ & $2.58 \pm 2.06$ & $1.68 \pm 0.88$ & $<0.001$ \\
Total Fatty Acid & $1.69 \pm 0.65$ & $1.20 \pm 0.56$ & $0.85 \pm 0.19$ & $<0.001$ \\
\hline
\end{tabular}

Note: Type IV = atheroma, Type $\mathrm{V}=$ fibroatheroma, Type VI = complex plaque; $\mathrm{p}$-value reached from ANOVA test; $\mathrm{n}=$ number of patients in group; $\mathrm{N}=$ total number of patients; $\mathrm{SD}=$ Standard Deviation.

Table 11. Association of type of plaque with diabetic and non-diabetic patients $(\mathrm{N}=80)$.

\begin{tabular}{cccccc}
\hline & & \multicolumn{3}{c}{ Type of plaque } & \multirow{2}{*}{ p value } \\
\cline { 3 - 5 } Diabetes mellitus & $\mathbf{n}$ & $\begin{array}{c}\text { Type IV } \\
\text { No. (\%) }\end{array}$ & $\begin{array}{c}\text { Type V } \\
\text { No. (\%) }\end{array}$ & $\begin{array}{c}\text { Type VI } \\
\text { No. (\%) }\end{array}$ & \\
\hline Yes & 39 & $19(48.7)$ & $14(35.9)$ & $6(15.4)$ & $0.004^{\text {s }}$ \\
No & 41 & $7(17.1)$ & $29(70.7)$ & $5(12.2)$ & \\
Total & 80 & $26(32.5)$ & $43(53.8)$ & $11(13.8)$ & \\
\hline
\end{tabular}

Data were expressed as frequency and percentage; Chi-square test was used to find the p-value and set at $<0.05$. $\mathrm{S}=$ significant; $\mathrm{N}=$ Total number of patients; $\mathrm{n}=$ Number of patients in group.

Among the non-diabetic patients, 7 patients (17.1\%) had Type IV plaque, and 29 patients $(70.7 \%)$ had Type V plaque and 5 patients (12.2\%) without diabetes had Type VI plaque. There was predominance of diabetic patients having type IV atheroma and non-diabetic having type $\mathrm{V}$ plaque. All were statistically significant.

\section{Conclusion}

This study was undertaken to find out the composition of human coronary 
atheroma in the perspective of Bangladesh. The study revealed that human coronary atheroma is contingent on the type of lesion. Grossly, the plaques were strong fibrous tissue of variable length with raised areas of yellow or white dots interspersed in the entire length of fibrous strand. Yellow dots were lipid rich and white dots which were rough and gritty suggested calcification and calcium deposition. Some lesions appeared as tanned yellow plaque in a white fibrous background with or without dark patchy areas. Tanned yellow indicated lipid deposition and the dark patches indicated necrotic core. Histologically, slides showed consistently the presence of less or more amount of fibrocollagenous tissue, calcification areas, cholesterol cleft, inflammatory cells and smooth muscle elements. Infrequently, thrombotic materials found inside the lumen of the plaque in complicated lesions also revealed in slides. The biochemical analysis of atherosclerotic lesion of Bangladeshi population revealed total cholesterol in the range of $0.20 \%-9.83 \%$, total fatty acids in the range of $0.47 \%-3.04 \%$. Also, there was more total cholesterol in diabetic patients as compared to non-diabetic patients.

\section{Acknowledgements}

We are grateful to the study committee and volunteers for agreeing to participate in the study and study staff members for their diligent effort. We are also very grateful to the Bangladesh Reference Institute for Chemical Measurements (BRiCM) for providing us for the laboratory facilities.

\section{Authorship Contribution}

Mayank Acharya is the principal investigator who is doing surgery and collection of atheroma etc. Sumiya Aktar, Md. Abu Hasan and Md. Moniruzzaman doing atheroma variables analyzed biochemically. Pranab Karmaker and Mala Khan wrote the paper. Mala Khan and Asit baran Adhikary were the supervisors of the work.

\section{Conflicts of Interest}

None of the authors has a relevant conflict of interest.

\section{References}

[1] Kouchoukos, N.T., Kirklin, J.K., Blackstone, E.H. and Hanley, F.L. (2013) Kirklin Barratt-Boyes Cardiac Surgery. 4th Edition, Elsevier Saunders, Philadelphia, p. 354.

[2] Weber, C. and Noels, H. (2011) Atherosclerosis: Current Pathogenesis and Therapeutic Options. Nature Medicine, 17, 1410-1422. https://doi.org/10.1038/nm.2538

[3] Ross, R., Glomset, J. and Harker, L. (1977) Response to Injury and Atherogenesis. The American Journal of Pathology, 86, 675-684.

[4] World Health Organization (2002) Bangladesh: WHO Statistical Profile. http://www.who.int/gho/countries/bgd.pdf?ua=1

[5] Sayeed, M.A., Mahtab, H., Sayeed, S., Begum, T., Khanam, P.A. and Banu, A. (2010) 
Prevalence and Risk Factors of Coronary Heart Disease in Rural Population of Bangladesh. Ibrahim Medical College Journal, 4, 34-43.

[6] Islam, M.A.K.M. and Majumder, A.A.S. (2013) Coronary Artery Disease in Bangladesh: A Review. Indian Heart Journal, 65, 424-435.

https://doi.org/10.1016/j.ihj.2013.06.004

[7] Rao, G.H.R. (2005) Coronary Artery Disease: Risk Factors, Pathophysiology and Prevention. Jaypee Med. Pub., New Delhi, 21-57.

[8] Moore, K.J. and Tabas, I. (2011) Macrophages in the Pathogenesis of Atherosclerosis. Cell, 145, 341-355. https://doi.org/10.1016/j.cell.2011.04.005

[9] Fahy, E., Subramaniam, S., Brown, H.A., Glass, C.K., Merrill, A.H., Murphy, R.C., et al. (2005) A Comprehensive Classification System for Lipids. Journal of Lipid Research, 46, 839-862. https://doi.org/10.1194/jlr.E400004-JLR200

[10] Ratnayake, W.N. and Galli, C. (2009) Fat and Fatty Acid Terminology, Methods of Analysis and Fat Digestion and Metabolism: A Background Review Paper. Annals of Nutrition and Metabolism, 55, 8-43. https://doi.org/10.1159/000228994

[11] Bhalodkar, N.C., Blum, S., Rana, T., et al. (2004) Comparison of Levels of Large and Small High-Density Lipoprotein Cholesterol in Asian Indian Men Compared with Caucasian Men in the Framingham Offspring Study. American Journal of Cardiology, 94, 1561-1563. https://doi.org/10.1016/j.amjcard.2004.08.040 